\section{Council of Europe experiments with remote sensing}

THE European Joint Committee on Scientific Cooperation, a committee of the Council of Europe, recently conducted what $M$ Andre Boulloche, its chairman, described as an experiment in democracy for Europe: a one-day parliamentary hearing on 'Europe's specific needs in the field of remote sensing' which was held in Toulouse last weekend. The aim of the hearing was to help "parliamentarians in their political decision-making" and to strengthen the democratic process by opening the hearing to the public.

The idea for such a hearing stemmed more from a growing dissatisfaction with the way in which Europe conducted its space programme than from concern over the remote sensing programme in particular. Attempts to implement a coherent European space policy, or even see through a European Space Agency (ESA) project, have often been thwarted by the desire of individual countries to pursue their own interests.

By holding a public hearing, the Council of Europe hoped to initiate interest in space policy as a European affair-both among the parliamentarians of its member states and among the public. Remote sensing was an appropriate topic to spark off that interest: first because it has already suffered from disagreement among ESA members over a future programme, and second because it is likely to have public appeal, being applicable to many practical problems.

The format of the hearing was based on that of Congressional hearings in the United States. The jury, a group of parliamentarians and their scientific advisers, questioned a 'group under challenge'. This group consisted of users of remote sensing from the member countries, and delegates from ESA, the national space agencies, and international organisations. The 'moderator', Mr Van Aal, whose task was to "stimulate a confrontation

\section{Erratum}

A typographical error occurred in the article 'Reprocessing nuclear fuel: for . . .' by Professor G. R. Bainbridge on page 2 of this volume. The first paragraph stated that $\mathrm{Mr}$ Justice Parker had recommended that BNFL built an oxide-fuel reprocessing plant at Dounreay. This should have read Windscale. We apologise for any confusion this may have caused. between the jury and the "group under challenge" sat between the two.
Several good cases were put forward for Europe building and operating its own satellite for remote sensing. At present Europe depends mainly on receiving satellite remote sensing data from United States satellites via Earthnet, ESA's European Network to Receive, Reprocess and Distribute Earth Resources Satellite Data. This consists of several receiving stations dotted around Europe, not all of which are yet operational. ESA also has plans to send remote sensing experiments on the first spacelab payload.

But a European satellite would not only relieve Europe of its dependence on the United States, it would also provide the opportunity of designing a satellite geared to Europe's needs and problems. NASA's Landsat satellites, for example, have a ground resolution of $40-80 \mathrm{~m}$, adequate for imaging American farms, but not the much smaller agricultural holdings of Europe. A ground resolution of 10-30 $\mathrm{m}$, however, could be developed for sensing intruments aboard a European satellite.

Another major problem with remote sensing for Europe is that much of the continent is covered with cloud for much of the time. But infrared imaging, microwave and aperture radar synthesis techniques are not affected by cloud cover. The latest Landsat satellite, launched earlier in the month, can take images in the thermal infrared, but microwave and aperture synthesis techniques are not yet fully operational. They could, however, be developed by an ESA member state to be incorporated into a Euro-

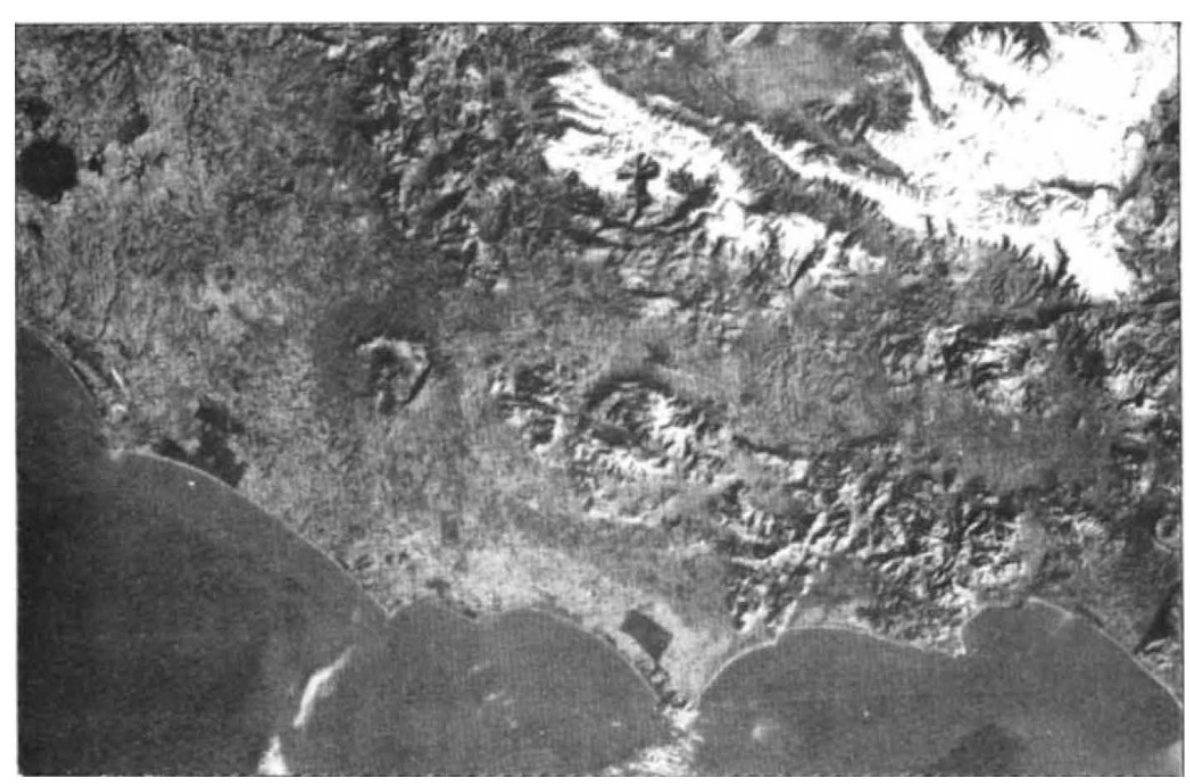

The area around Rome photographed by NASA's Landstat satellite pean satellite for launch in the mid 1980s.

Although the format of the hearing could be compared to that of a United States Congressional hearing, the tone of the debate was very different: it lacked the hard questioning needed to work out a policy. But perhaps that could not be expected from politicians coming from many different countries (except for a notable absentee, the UK) where remote sensing is not a hot political issue. If the hearing did inform and make them aware of an issue of concern to Europe which they would otherwise not have known about, then it could be said to have been a success.

One question, however, raised hackles-on whether France had the capability to develop a satellite incorporating new techniques. $\mathrm{M}$ A. Lebeau, director of future programmes at ESA, refused to answer. The French are already building their own remote sensing satellite, SPOT, for launch in 1983. At the end of last year ESA rejected the SPOT proposal. It is similar to NASA's Landsat satellite, and does not use microwave imaging or aperture radar techniques. ESA is currently preparing a programme proposal for a European remote sensing satellite which it hopes to have ready by the end of this year.

The next step is for the Council of Europe's Committee on Science and Technology to draw up a draft recommendation for discussion by its Parliamentary Assembly. M Boulloche summed up the hearing by saying that "European parliamentarians will not leave with any deep rooted conviction about remote sensing. But let's not worry-the United States have held two hearings and still haven't made up their minds". Judy Redfearn 